\title{
Characterization of electron density of states in laser-superposed channeling regime - CORRIGENDUM
}

\section{Corrigendum}

Cite this article: Berec V (2019). Characterization of electron density of states in laser-superposed channeling regime CORRIGENDUM. Laser and Particle Beams 37, 311. https://doi.org/10.1017/

S026303461900051X

First published online: 27 June 2019

\section{Vesna Berec}

doi:10.1017/S0263034614000482, Published by Cambridge University Press, 10 October 2014.

In the original publication of this article, there was an error present in the author's affiliation and correspondence information. The correct affiliation and correspondence for the author is as follows:

The University of Belgrade, St. trg 1, 11000 Belgrade, Serbia.

Address correspondence and reprint requests to: Vesna Berec, The University of Belgrade, St. trg 1, 11000 Belgrade, Serbia. E-mail: vesna.berec@gmail.com

The original article has been updated to reflect the change.

\section{Reference}

Berec V (2015) Characterization of electron density of states in laser-superposed channeling regime. Laser and Particle Beams 33, 1-9. 